\title{
The relationship between carotid intima-media thickness and serum secreted frizzled-related protein-4 and dipeptidyl peptidase-4 in diabetic patients with cardiovascular diseases
}

\author{
Senyigit $\mathrm{A}^{1}$, Uzun $\mathrm{H}^{2}$, Gultepe $\mathrm{I}^{3}$, Konukoglu $\mathrm{D}^{2}$ \\ Department of Internal Medicine, Istanbul Medicine Hospital, Medical School, University of Biruni, \\ Istanbul, Turkey. huzun59@hotmail.com
}

\begin{abstract}
We investigated the association between carotid intima-media thickness (CIMT) with clusterin (CLU), amylin, secreted frizzled-related protein-4 (SFRP-4), glucagon-like peptide-1 (GLP-1) levels, and dipeptidyl peptidase-4 (DPP-4) in type 2 diabetes mellitus (T2DM) individuals with or without coronary artery disease (CAD). This study consisted of four groups: control group (mean ages: $50.3 \pm 10.7$ years; 20 females and 15 males), diabetic group (DM; mean ages: 53.9 $\pm 11.1 ; 14$ females and 23 males), CAD group (mean ages: $60.1 \pm 43.5 ; 17$ females and 17 males) and CAD+DM group (mean ages: $62.6 \pm 11.8$ years; 18 females and 18 males). CIMT levels in both CAD and CAD+DM groups are higher than those in controls. CIMT levels in CAD+DM group are also significantly higher than those in DM group. Left external carotid artery (ECA) was found different from controls only in DM group. The levels of SFRP-4 in control group were significantly lower than those in DM, CAD and CAD+DM groups. Serum GLP-1 $1_{\text {total }}$ levels were found to be significantly low in CAD+DM group when compared to control group. DPP-4 and SFRP-4 levels may be a predictive marker for atherosclerosis in diabetes while particularly in diabetes, they correlate well with HOMA-IR. CIMT has the potential to be a clinically useful predictor of vascular risk in diabetic patients with CAD (Tab. 3, Fig. 2, Ref. 39). Text in PDF www.elis.sk.

KEY WORDS: type 2 diabetes mellitus, carotid intima-media thickness, glucagon-like peptide-1, dipeptidyl peptidase-4, clusterin, amylin, secreted frizzled-related protein-4.
\end{abstract}

\section{Introduction}

Diabetes mellitus (DM) has reached epidemic proportions worldwide, and its prevalence is rising. The implications of DM diagnosis are as severe as those of coronary artery disease (CAD). $\mathrm{DM}, \mathrm{CAD}$ and heart failure are interacting dynamically. While there has been a considerable improvement in the management of patients with $\mathrm{CAD}$, coronary event rates among patients with DM remain heightened. Enhanced cardiovascular risk stratification based on biomarkers, symptoms and classical risk factors should be performed in patients with pre-existing DM $(1,2)$.

Carotid intima-media thickness (CIMT), arterial stiffness, and epicardial fat thickness are useful non-invasive markers of subclinical atherosclerosis (3). All carotid B-mode real-time ultrasound measurements were performed by the same experienced physician, who was blinded to the patient's urine albumin status.

${ }^{1}$ Department of Internal Medicine, Istanbul Medicine Hospital, Medical School, University of Biruni, Istanbul, Turkey, ${ }^{2}$ Department of Biochemistry, Cerrahpasa Faculty of Medicine, Istanbul University-Cerrahpasa, Istanbul, Turkey, and ${ }^{3}$ Department of Internal Medicine, Medicine Faculty, Altınbas University, Istanbul, Turkey

Address for correspondence: $\mathrm{H}$. Uzun, Department of Medical Biochemistry, Cerrahpasa Faculty of Medicine, Istanbul University, 34303, Cerrahpasa - Istanbul, Turkey.

Phone: +90.212 .4143056 , Fax: +90.212 .6332987$
As previously described, the measurements of IMT were performed in both right and left common carotid arteries (CCAs), external carotid arteries (ECA) and internal carotid arteries (ICAs) (4). It has been reported that CIMT remained stable in type 2 DM (T2DM) patients who received comprehensive intensive therapy, suggesting that multi-factorial intensive therapies might have a potential in reducing macro-vascular events in these patients (5).

Amylin, or islet amyloid polypeptide (IAPP), is a neuroendocrine hormone co-localized, co-secreted and co-packaged with insulin from pancreatic $\beta$ cells. Amylin functions as part of the neuroendocrine pancreas and contributes to glucose homeostasis with other two pancreatic islet hormones, namely insulin and glucagon (6).

Secreted frizzled-related protein 4 (SFRP-4) is a member of the SFRP family. SFRPs act as modulators of the wingless-type mouse mammary tumor virus integration site family (Wnt) signaling pathway. A large number of diabetes-associated factors are studied in the Wnt signaling pathway (6). Individuals having increased levels of SFRP-4 in the blood are five times more likely to develop diabetes in the coming years (7).

The two major incretin hormones, glucagon-like peptide(GLP-1) and glucose-dependent insulinotropic polypeptide (GIP, previously known as gastric inhibitory polypeptide), are secreted from the small intestine in response to meal ingestion, and act on specific receptors on $\beta$-cells. Both are metabolized by the enzyme dipepti- 
dyl peptidase-4 (DPP-4). The cleavage can be blocked by specific DPP-4 inhibitors, resulting in increased plasma concentrations of the intact peptides and improved glucose tolerance. DPP-4 inhibitors have been proposed as a possible pharmacological treatment of T2DM (8), and many compounds are presently in clinical development (8-10). GLP-1 circulates in many different (degraded) forms in the blood, some of which are biologically active and others are not.

Clusterin (CLU) apolipoprotein J (here after CLU) is a 449amino acid disulfide-linked heterodimeric glycoprotein composed of $\alpha$ and $\beta$ subunits and generated by a single cleavage in the single-chain precursor protein. However, CLU was not found in the normal aorta but was rather localized in aortas with diffuse, intimal thickening or atherosclerotic lesions; the extend of CLU distribution in the aortic wall increased during the progression of the disease from fatty acid streaks to advanced atherosclerosis (11-13).

CAD is the cause of death in more than half of all diabetic patients, and many are debilitated by symptoms of congestive heart failure or angina. Therefore, this study aimed to explore the association between the concentrations of serum amylin, SFRP4, GLP- $1_{\text {total }}$, GLP-1 $1_{\text {active }}$, DPP-4 and CLU and CIMT and to investigate whether these parameters have atherosclerotic effects in T2DM individuals.

\section{Materials and methods}

\section{Subjects}

The protocol was approved by the Ethics Committee of Cerrahpasa Medical Faculty and was conducted in accordance with the Declaration of Helsinki. All participants were informed about the survey and voluntarily signed and dated the consent form. This case-control study was conducted in Department of Internal Medicine, Medicine Hospital, and Istanbul in period from April to October 2017. All subjects were of Turkish descent. Pregnant women, patients with renal, hepatic, rheumatic, malign or endocrine diseases, smokers and subjects taking drugs which could affect our results were excluded.
Studied groups are classified as follows;

General characteristics of studied groups are given in Table 1.

Control group: Thirty-five healthy subjects who have no endocrine, vascular, cardiac or inflammatory disease were accepted as control group (mean ages: 50.3 \pm 10.7 years; 20 females and 15 males). An oral questionnaire was applied to the subjects and none of our subjects declared evidence of family history of diabetes. They had neither diabetes, nor glucose intolerance confirmed with oral glucose tolerance test (OGTT).

Type 2 diabetes group (DM): Patients with newly diagnosed T2DM (mean ages: 53.9 \pm 11.1 years; 14 females and 23 males) were included in this study. For the diagnosis of DM, guidelines of American Diabetes Association (ADA) criteria were used (14). Diabetic patients involved in our study have not been under medical therapy.

$C A D$ group: Thirty-four patients (mean ages: $60.1 \pm 43.5$ years; 17 females and 17 males) with coronary artery disease were studied. Fifty-five percent of the patients had hypertension and were under therapy with beta blockers (60\%), thiazide (35\%) and/or ACE inhibitors (13\%).

$C A D+D M$ group: Thirty-six diabetic patients (mean ages: $62.6 \pm 11.8$ years; 18 females and 18 males) with coronary artery diseases were enrolled in our study. All of the diabetic patients were under therapy for diabetes with insulin (23\%) and/or metformin ( $80 \%$ ). Eighty-six percent of diabetic patients in this group had hypertension and were under therapy with beta blockers (50\%), thiazide (30\%) and /or ACE inhibitors (15\%). Dyslipidemic diabetic patients (72\%) were using antihyperlipidemic drugs such as statins.

Ultrasonographic measurement of carotid intima-media thickness (CIMT)

The extracranial carotid arteries were examined using a standardized protocol by the same radiologist. Ultrasonographic examinations were performed in a quiet, temperature-controlled room $\left(22^{\circ} \mathrm{C}\right)$. After $10 \mathrm{~min}$ of rest, the examinations were performed with a color Doppler ultrasound unit [General electrics (GE) Logiq

Tab. 1. General characteristics of studied groups.

\begin{tabular}{|c|c|c|c|c|}
\hline & Controls $(n=35)$ & $\mathrm{DM}(\mathrm{n}=37)$ & $\mathrm{CAD}(\mathrm{n}=34)$ & $\mathrm{CAD}+\mathrm{DM}(\mathrm{n}=36)$ \\
\hline Ages (years) & $50.3 \pm 10.7$ & $53.9 \pm 11.1$ & $60.1 \pm 13.5$ & $62.6 \pm 11.8$ \\
\hline $\operatorname{Sex}(\mathrm{F} / \mathrm{M})$ & $20 / 15$ & $14 / 23$ & $17 / 17$ & $18 / 18$ \\
\hline Systolic Blood Pressure (mmHg) & $115.9 \pm 10.6$ & $131.7 \pm 10.2^{\mathrm{b}}$ & $124.6 \pm 14.4$ & $132.7 \pm 15.4^{\mathrm{b}}$ \\
\hline Diastolic Blood Pressure (mmHg) & $72.3 \pm 6.8$ & $79.4 \pm 7.2$ & $75.4 \pm 9.4$ & $77.7 \pm 10.2$ \\
\hline Duration of diabetes (years) & - & $5.8 \pm 5.5$ & - & $6.2 \pm 5.8$ \\
\hline Duration of CAD & - & - & $6.3 \pm 2.7$ & $5.5 \pm 3.3$ \\
\hline FBG (mg/dL) & $88.14 \pm 4.95$ & $133.15 \pm 34.42^{\mathrm{d}}$ & $98.81 \pm 10.51^{\mathrm{d}}$ & $149.89 \pm 57.91^{\mathrm{h}}$ \\
\hline Insulin $(\mu \mathrm{IU} / \mathrm{mL})$ & $12.19 \pm 4.91$ & $16.08 \pm 9.23^{\mathrm{b}}$ & $13.52 \pm 3.61$ & $18.29 \pm 11.35^{\mathrm{c}, \mathrm{f}}$ \\
\hline Total cholesterol (mg/dL) & $150.0 \pm 48.5$ & $202.9 \pm 39.2^{\mathrm{c}}$ & $168.6 \pm 41.9^{c}$ & $196.3 \pm 39.1^{\mathrm{c}}$ \\
\hline HDL-cholesterol (mg/dL) & $49.9 \pm 16.9$ & $42.2 \pm 15.4^{\mathrm{a}}$ & $36.8 \pm 10.4^{\mathrm{d}}$ & $38.8 \pm 9.1^{\text {d. } f}$ \\
\hline LDL-cholesterol (mg/dL) & $94.5 \pm 34.9$ & $104.8 \pm 36.9$ & $104.8 \pm 36.8$ & $99.8 \pm 40.1$ \\
\hline Triglycerides (mg/dL) & $119.6 \pm 47.7$ & $211.5 \pm 54.8^{\mathrm{b}}$ & $138.6 \pm 84.8$ & $135.5 \pm 70.9$ \\
\hline Uric Acid (mg/dL) & $5.26 \pm 1.28$ & $5.42 \pm 1.39$ & $6.40 \pm 1.64^{\mathrm{c}, \mathrm{e}}$ & $5.54 \pm 1.31$ \\
\hline Homocysteine $(\mu \mathrm{mol} / \mathrm{L})$ & $9.77 \pm 3.83$ & $10.41 \pm 2.48$ & $14.3 \pm 8.08^{\mathrm{c}, \mathrm{e}}$ & $11.86 \pm 4.81$ \\
\hline
\end{tabular}

$\overline{\mathrm{DM}}$ - diabetes mellitus, CAD - coronary artery diseases, CAD+DM - diabetic patient with coronary artery diseases, HOMA-IR - Homeostatic Model Assessment for Insulin Resistance. Comparison with control group ${ }^{\mathrm{a}} \mathrm{p}<0.05,{ }^{\mathrm{b}} \mathrm{p}<0.015,{ }^{\mathrm{c}} \mathrm{p}<0.005,{ }^{\mathrm{d}} \mathrm{p}<0.001$

Comparison with diabetes mellitus group ${ }^{\mathrm{e}} \mathrm{p}<0.01,{ }^{\mathrm{f}} \mathrm{p}<0.005$, Comparison with CAD group ${ }^{\mathrm{g}} \mathrm{p}<0.001$

Values other than HOMO-IR are given as mean \pm standard deviation. * Result were given as median and interquartile range (25th and 75 th perce 
S7 Expert, 9 L MHz transducer (prob), USA] equipped with a 5-10-MHz transducer. External carotid artery (ECA) was scanned only for atherosclerotic plaques. IMT was measured across a $1-\mathrm{cm}$ segment of both the right and left sides of the near and far walls of the distal common carotid artery (CCA), far wall of the carotid bulb ECA and internal carotid artery (ICA). The proximal $1.5 \mathrm{~cm}$ of the ICA was measured. Atherosclerotic plaque was defined as a distinct area protruding into the vessel lumen. This protrusion had to be at least $50 \%$ thicker than the surrounding areas. When plaques were present, measurements were made from their outside borders. The mean of all measurements from eight locations was taken as an overall measure of CIMT. The location, size, number and hemodynamic effects of the atherosclerotic plaques were determined with the help of grayscale, color Doppler and spectral Doppler ultrasound. All measurements were made at the time of the scanning of frozen images from the longitudinal scans using the machine's electronic caliper. The radiologist was blinded to the clinical diagnoses. Intra-observer was assessed by a repeated evaluation of 15 randomly selected participants after two weeks. Intra-observer agreement was good $(\kappa=0.82)$.

\section{Sample collection and measurements}

Fasting venous blood samples were drawn between 8 and 10 a.m., after an overnight fasting (10-12 hours). Blood samples were drawn via brachial veins in brachial fossa into plain tubes and tubes containing anticoagulant [ethylenediaminetetraacetic acid (EDTA)]. Samples were centrifuged for 10 minutes at 4,000 rpm at $40{ }^{\circ} \mathrm{C}$. Biochemical tests were performed immediately. For the determination of other parameters serum aliquots were frozen and stored immediately at $-80^{\circ} \mathrm{C}$ until further analysis.

\section{Measurement of serum GLP-1 concentrations}

Serum GLP- $1_{\text {total }}$ and GLP-1 $1_{\text {active }}$ were assayed by antibody sandwich ELISA kit (Cat. EZGLP1T-36K, and Cat. EGLP-35K, EMP Millipore Corporation, USA). Results were expressed as pM. The sensitivity of GLP-1 total ELISA kit was $1.5 \mathrm{pM}$. Intra and inter-CV for GLP- $1_{\text {total }}$ were $6.7 \%$ and $11.3 \%$, respectively. The lowest level of GLP- $1_{\text {active }}$ that could be detected by this assay was $2 \mathrm{pM}$. Intra and inter-CV for GLP-1 levels were $6.5 \%$ and $10.4 \%$, respectively.

\section{Measurement of serum DPP-4 activity}

Levels of serum DPP-4 were also assayed by antibody sandwich ELISA kit (Human DPP-4 kit Cat. No. YHB1023 Hu, ARP American Research Products, Inc. USA). Results of DPP-4 were expressed as pg per mL of serum. The lowest level of DPP-4 that could be detected by this assay was $25 \mathrm{pg} / \mathrm{mL}$. Intra- and inter-CV were $8.1 \%$ and $10.5 \%$, respectively.

\section{Measurement of serum CLU concentrations}

Levels of serum CLU were determined by antibody sandwich ELISA kit assay (Human CLU ELISA Kit, Cat.No: YHB0754 Hu, ARP American Research Products, Inc. USA). Results of CLU levels were expressed as $\mu \mathrm{g}$ per $\mathrm{mL}$ of serum $(\mu \mathrm{g} / \mathrm{mL})$. The lowest level of CLU that could be detected by this assay was $0.24 \mu \mathrm{g} /$ $\mathrm{mL}$. Intra and inter variations of the coefficient $(\mathrm{CV})$ were $6.2 \%$ and $8.4 \%$, respectively.

\section{Measurement of serum amylin concentrations}

Levels of serum amylin were assayed by ELISA kit (Human Amylin Cat No. YHB0161 Hu, ARP American Research Products, Inc. USA). Results were expressed as pg per $\mathrm{ml}$ of serum ( $\mathrm{pg} / \mathrm{mL})$. The sensitivity of this kit was $1.36 \mathrm{pg} / \mathrm{mL}$. Intra and inter-CV were $7.1 \%$ and $9.0 \%$, respectively.

\section{Measurement of serum SFRP-4 concentrations}

Levels of serum SFRP-4 were determined by antibody sandwich ELISA kit (Human SFRP-4 ELISA Kit, Cat No. E2327 Hu, Bioassay Technology Laboratory, USA). Results were expressed as ng per $\mathrm{ml}$ of serum $(\mathrm{ng} / \mathrm{mL})$. The lowest level of SFRP4 that can be detected by this assay was $1.5 \mathrm{pM}$. CV for intra-assay and inter-assay were $5.5 \%$ and $11.2 \%$, respectively.

Glucose, total cholesterol, HDL cholesterol, LDL cholesterol and triglyceride levels were determined by enzymatic methods (Roche Cobas Integra 400, Roche Diagnostics Ltd. Germany). Insulin concentrations were measured by electrochemiluminescence immunoassay (ECLIA) method on Roche-Hitachi E170 (Roche/ Hitachi MODULAR Analytics Combination Systems, Roche Diagnostics, USA). HbA1c determination was based on HPLC (Variant Turbo II, Bio-Rad Laboratories, Inc. USA).

HOMA-IR (Homeostatic Model Assessment for Insulin Resistance) was calculated according to the formula as follows: fasting insulin (microU/L) x fasting glucose $(\mathrm{nmol} / \mathrm{L}) / 22.5$.

\section{Statistical analysis}

Statistical analysis was performed using SPSS 20.0 version for Windows Statistical Program (SPSS, Chicago, IL, USA). All data were expressed as means \pm standard deviation (SD). Descriptive statistics were obtained, and data were tested for normality using the Kolmogorov-Smirnov test for Gaussian distribution. For

Tab. 2. Carotid intima-media thickness $(\mathrm{mm})$ in groups of controls type 2 diabetic patients with (CAD+DM) or without coronary artery disease (DM) and patients with coronary artery disease (CAD).

\begin{tabular}{llllll}
\hline Groups & Right CCA & Right ICA & Right ECA & Left CCA & Left ICA \\
\hline Controls & $0.68 \pm 1.06$ & $0.77 \pm 1.23$ & $0.51 \pm 0.65$ & $0.58 \pm 0.80$ & $0.56 \pm 0.77$ \\
DM & $0.75 \pm 0.26$ & $0.73 \pm 0.24$ & $0.66 \pm 0.20$ & $0,78 \pm 0.22$ & $0.78 \pm 0.26$ \\
CAD & $0.97 \pm 0.26^{\mathrm{b}}$ & $1.01 \pm 0.28^{\mathrm{b}}$ & $0.85 \pm 0.19^{\mathrm{b}}$ & $1.05 \pm 2.79^{\mathrm{b}}$ & $0.66 \pm 0.16^{\mathrm{a}}$ \\
CAD+DM & $0.90 \pm 0.32^{\mathrm{b}, \mathrm{c}}$ & $0.96 \pm 0.29^{\mathrm{b}, \mathrm{c}}$ & $0.83 \pm 0.23^{\mathrm{b}, \mathrm{c}}$ & $1.03 \pm 0.37^{\mathrm{b}, \mathrm{c}}$ & $1.06 \pm 0.31^{\mathrm{b}, \mathrm{c}}$ \\
\hline
\end{tabular}

CCA - common carotid artery, ICA - internal carotid artery, ECA - external carotid artery,

Comparison with control group ${ }^{\mathrm{a}} \mathrm{p}<0.05,{ }^{\mathrm{b}} \mathrm{p}<0.001,{ }^{\mathrm{b}}$ Comparison $\mathrm{n}$ with diabetes mellitus group ${ }^{\mathrm{c}} \mathrm{p}<0.001$ 
Tab. 3. Serum levels of clusterin (CLU), amylin, dipeptidyl- peptidase-4 (DPP-4), secreted frizzled-related protein 4 (SFRP-4), glucagon like peptide -1(GLP-1) $)_{\text {total }}$ and GLP-1 $1_{\text {active }}$ in groups of controls, diabetic patients with (CAD+DM) and without coronary artery disease (DM) and patients with coronary artery disease (CAD).

\begin{tabular}{lcccc}
\hline & Control $(\mathrm{n}=35)$ & $\mathrm{DM}(\mathrm{n}=37)$ & $\mathrm{CAD}(\mathrm{n}=34)$ & $\mathrm{CAD}+\mathrm{DM}(\mathrm{n}=36)$ \\
\hline $\mathrm{CLU}(\mu / \mathrm{mL})$ & $22.2(19.6-37.5)$ & $27.1(19.8-38.2)$ & $20.4(19.1-20.3)$ & $28.1(19.4-59.9)$ \\
Amylin $(\mathrm{pg} / \mathrm{mL})$ & $410.1(358.5-691.0)$ & $436.9(328.6-611.1)$ & $416.2(361.2-567.8)$ & $428.9(350.9-767.4)$ \\
DPP-4 $(\mathrm{pg} / \mathrm{mL})$ & $3496(3169-6387)$ & $2861(2213.1-5004.1) \mathrm{a}$ & $2617(2265.7-4445.4) \mathrm{b}$ & $3191.4(2017.3-7157.4)$ \\
SFRP-4 $(\mathrm{ng} / \mathrm{mL})$ & $1.41(1.24-1.67)$ & $1.70(1.51-2.45) \mathrm{c}$ & $1.58(1.31-2.55) \mathrm{b}$ & $2.02(1.47-3.47) \mathrm{c}$ \\
GLP-1total $(\mathrm{pM})$ & $91.9(73.3-106.3)$ & $39.0(33.9-49.9) \mathrm{c}$ & $43.4(31.2-52.9) \mathrm{c}$ & $51.4(34.8-71.5) \mathrm{c}, \mathrm{d}$ \\
GLP-1active $(\mathrm{pM})$ & $3.92(3.40-5.16)$ & $4.71(3.50-5.93)$ & $5.25(3.63-6.10)$ & $4.25(3.38-7.64)$ \\
\hline
\end{tabular}

$\mathrm{DM}$ - type 2 diabetes mellitus, CAD - coronary artery disease, CAD+DM - type 2 diabetic patients with CAD.

Comparison with control group ${ }^{\mathrm{a}} \mathrm{p}<0.01,{ }^{\mathrm{b}} \mathrm{p}<0.005,{ }^{\mathrm{c}} \mathrm{p}<0.001$, Comparison with DM group, ${ }^{\mathrm{d}} \mathrm{p}<0.05$

Result were given as median and interquartile range ( 25 th and 75 th percentiles)

comparison of parameters with normal distribution, parametric tests were used while for comparison of parameters with abnormal distribution, non-parametric tests were used. For this purpose, one-way ANOVA, unpaired student-t, Kruskal-Wallis and MannWhitney U tests were used. CLU, amylin, DDP-4, SFRP-4, GLP$1_{\text {total }}$, GLP-1 $1_{\text {active }}$ and HOMA-IR showed abnormal distribution. Tukey's test (for parametric analysis) and Dunn's tests (for nonparametric analysis) were used as post-hoc tests. For parametric tests, continuous variables are expressed as mean \pm standard deviation, while for non-parametric tests, data are expressed as median and interquartile range (25th and 75th percentiles). Relationships between variables were assessed with Pearson's or Spearman's correlation coefficient. Power analysis was used to perform calculations on sample size, effect size, and statistical power. The minimal significance $(\alpha)$ and statistical power $(1-\beta)$ were set at 0.05 and 0.80 , respectively. A p value equal to or lower than 0.05 was considered statistically significant.

\section{Results}

Fasting plasma glucose concentration in patients in DM group, $\mathrm{CAD}$ and $\mathrm{CAD}+\mathrm{DM}$ groups was significantly higher than that in controls (for each $p<0.001$ ). The highest plasma glucose levels were obtained from CAD+ DM groups. HbA1c levels in DM and $\mathrm{CAD}+\mathrm{DM}$ groups were significantly higher than in control group $(\mathrm{p}<0.001)$. There was also a significant difference in $\mathrm{HbA} 1 \mathrm{c} \mathrm{lev-}$ els between $\mathrm{CAD}$ and $\mathrm{CAD}+\mathrm{DM}$ groups $(\mathrm{p}<0.001)$. Plasma total cholesterol levels in controls and CAD groups were significantly lower than in DM and CAD+DM groups $(\mathrm{p}<0.005$ and $\mathrm{p}<0.005$, respectively). HDL cholesterol levels in control group were found to be higher than in DM, CAD and CAD $+\mathrm{DM}$ groups $(\mathrm{p}<0.05, \mathrm{p}$ $<0.001$ and $\mathrm{p}<0.005$, respectively). When compared to control group, plasma triglycerides levels were higher only in DM group $(p<0.01)$. There was no significant difference in LDL cholesterol levels among groups. The duration of diabetes in the DM group was not significantly different from that in the CAD+DM group. Uric acid and homocysteine levels in CAD group were significantly higher than in DM group (for each $\mathrm{p}<0.01$ ) and control group (for each $\mathrm{p}<0.005$ ). Uric acid and homocysteine levels in DM group were not different from those in $\mathrm{CAD}+\mathrm{DM}$ group. Systolic blood pressure in $\mathrm{DM}$ and $\mathrm{CAD}+\mathrm{DM}$ groups were significantly higher than in control group (for each $\mathrm{p}<0.01$ ).
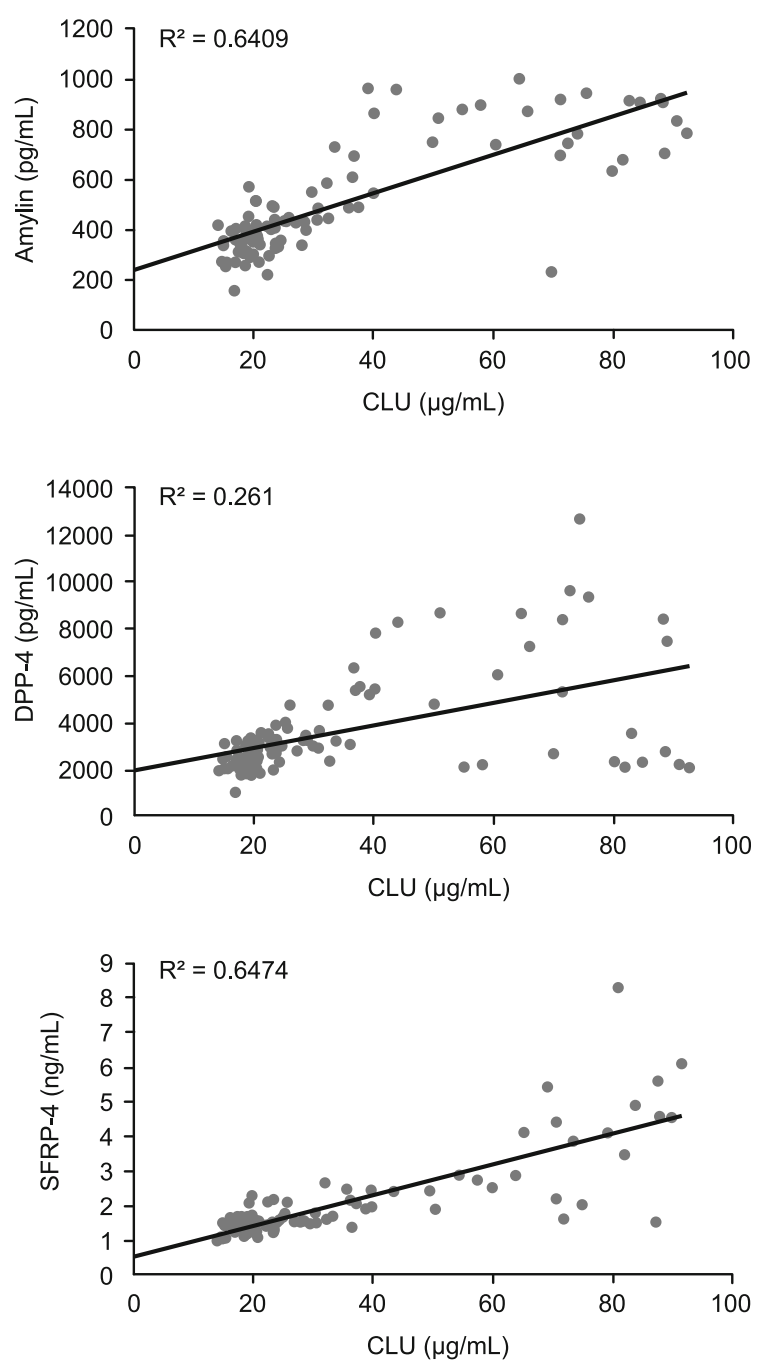

Fig. 1. Correlation analysis between CLU levels and amylin, DPP-4 and SFRP-4 levels in sum of the patients groups. Significant positive correlation was found between CLU levels and amylin ( $r: 0.804$, $p<0.01)$, DPP-4 (r:0.524, $p<0.01)$ and SFRP-4 levels $(p<0.800, p<0.01$. $)$

CIMT levels in studied groups were given in Table 2. Left ECA was found different from that in controls only in DM group $(p<0.05)$. ICA levels in both CAD and CAD+DM groups were higher than those in controls (for each comparison $p<0.001$ ). 

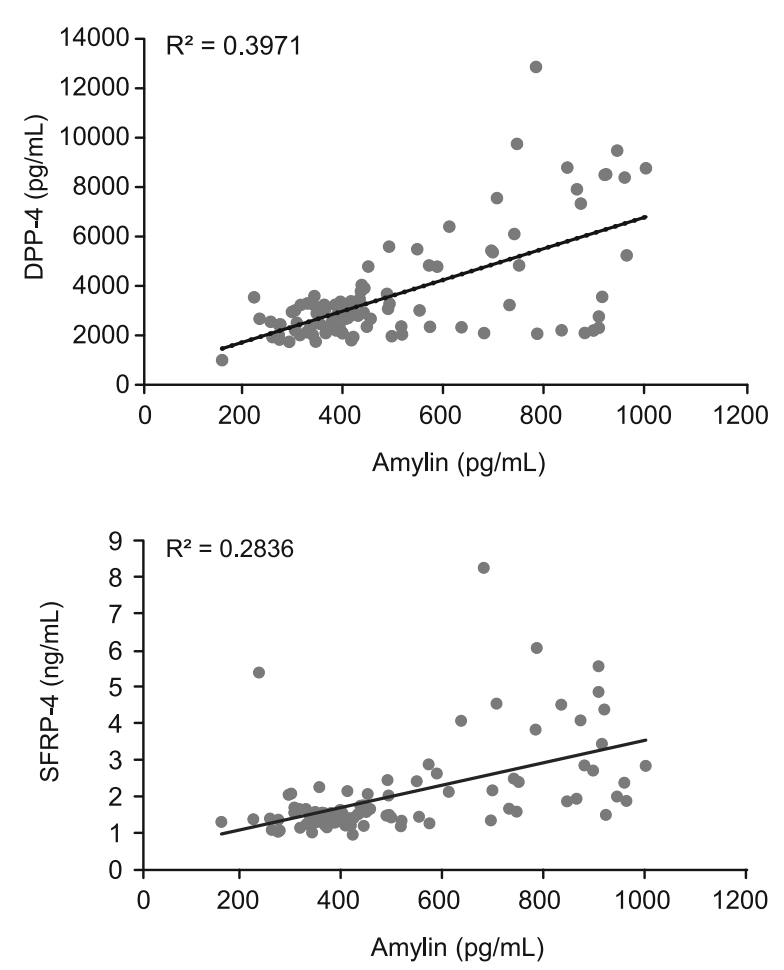

Fig. 2. Correlation analysis between amylin levels and DPP-4 and SFRP-4 levels in sum of the patients groups Significant positive correlation was found between CLU levels and amylin $(r: 0.804, p<0.01)$, DPP-4 (r:0.524, $p<0.01)$ and SFRP-4 levels $(p<0.800, p<0.01)$.

There was no significant difference in ICA levels between CAD and $\mathrm{CAD}+\mathrm{DM}$ groups. ICA levels in $\mathrm{CAD}+\mathrm{DM}$ group was significantly higher than those in DM group (for each comparison $\mathrm{p}<0.001)$.

We found that serum CLU, amylin and GLP-1 ${ }_{\text {active }}$ levels did not differ among groups (Tab. 3). When compared with controls, DM, CAD groups have low DPP-4 $(\mathrm{p}<0.01$ and $\mathrm{p}<0.005)$ and GLP- $1_{\text {total }}(\mathrm{p}<0.001$ and $\mathrm{p}<0.001)$ concentration. SFRP-4 levels in control group were significantly lower than those in DM $(\mathrm{p}<$ $0.005), C A D(p<0.005)$ and $C A D+D M(p<0.001)$ groups. Serum GLP- ${ }_{\text {total }}$ levels in CAD+DM group were found to be significantly lower than those in control group. There was also a significant difference in GLP- $1_{\text {total }}$ between CAD+DM and DM groups $(\mathrm{p}<0.05)$.

When we performed a correlation analysis in sum of the groups, we found correlation neither between CIMT and studied parameters, nor in lipid parameters. Significant positive correlation was found between CLU levels (Fig. 1) and amylin (r: 0.804, p < 0.01 ), DPP-4 (r: 0.524, p < 0.01) and SFRP-4 levels ( $<<0.800 ; \mathrm{p}$ $<0.01$ ). Serum amylin levels were correlated with DPP-4 (r: 0.644 , $\mathrm{p}<0.01$ ) and (r: 0.528; p < 0.01) (Fig. 2). A significantly weak positive correlation was found between DPP-4 and GLP-1 ${ }_{\text {total }}(\mathrm{r}$ : $0.205 ; \mathrm{p}<0.05)$. GLP- $1_{\text {total }}$ levels were negatively correlated with GLP- $1_{\text {active }}$ levels $(\mathrm{r}:-0.222 ; \mathrm{p}<0.05)$. There was a significantly weak positive correlation between HOMA-IR and SFRP-4 levels (r: 0.244; p $<0.05$ ).

\section{Discussion}

Type $2 \mathrm{DM}$ is a complex disease with concomitant risk factors for the development of cardiovascular disorders such as atherosclerosis and hypertension. Atherosclerotic macrovascular disease is the leading cause of death in type 2 diabetes and CIMT is increased in patients with T2DM (4). This study showed that only in DM group, left ECA was found to be different from that of controls. ICA levels in both CAD and CAD+DM groups were higher than those in controls. ICA levels in CAD+DM group were higher than those in DM group. This is supported by the independent association between studied parameters, as well as lipids parameters and CIMT in T2DM patients which is likely due to atherosclerosis characterized by the pathogenesis of vascular complications of diabetes.

Amylin, which is considered the primary culprit for $\beta$-cell loss in T2DM patients, is synthesized in $\beta$-cells of the pancreas from its precursor proamylin and plays an important role in early intracellular amyloid formation as well (15). Similarly to our previous study, the serum amylin levels in present study did not differ among groups (16). In recent years, however, the results of studies in T2DM patients are conflicting. Zheng et al (15) found that the serum levels of amylin in the three groups (normal glucose tolerance (NGT) group, patients with impaired glucose regulation (IGR) and T2DM) had no significant differences. The serum proamylin levels were significantly higher in patients with IGR and T2DM than in control subjects. It appears that proamylin is more important and exerts a more significant effect than amylin. Skovronsky et al (17) found that proamylin might have a more severe cell toxicity than amylin and thus could play an important role in the deposition of islet amyloid. Qiu et al (18) showed that subjects with a long and chronic duration of diabetes were more likely to take insulin treatment and have reduced secretion of amylin. However, further experiments are needed to clarify the role of proamylin and amylin.

The role of CLU in attenuation of inflammation and reverse cholesterol transfer makes this molecule a potential candidate as a marker for cancer, CVD, DM, and metabolic syndrome. An important source of CLU in plasma is associated with HDL particles. In present study, HDL cholesterol levels are found to be higher in control group than in $\mathrm{DM}, \mathrm{CAD}$ and $\mathrm{CAD}+\mathrm{DM}$ groups. However, we found that serum CLU levels did not differ among groups. In our study, a significant positive correlation was found between CLU levels and amylin levels. Trougakos et al (19) found increased serum CLU levels in T2DM and posited that CLU might be a useful biomarker for detecting an early stage of diabetic retinopathy. They have also demonstrated that plasma CLU levels increase significantly in patients with T2DM which is a well-characterized risk factor for atherosclerosis. Study of Cai et al (20) suggested that plasma CLU concentration increased and was negatively correlated with memory performance in T2DM patients with mild cognitive impairment (MCI). Circulating CLU is associated with insulin resistance in human subjects (21). Future studies will need to clarify the exact role of CLU associated with atherosclerosis in T2DM patients with or without CAD. 
SFRP-4 is a regulator of insulin exocytosis in murine and human islet cells. Our data demonstrate that control group has lower SFRP-4 levels than DM, CAD and CAD+DM groups. We found that there was also a significant difference in SFRP-4 levels between DM, CAD and CAD+DM groups. There was also a significantly weak positive correlation between HOMA-IR and SFRP-4 levels. Mahdi et al (22) found that serum SFRP-4 in was associated with elevated fasting glucose and reduced disposition index. However, it was also associated with impaired insulin sensitivity, indicating that the protein could have a plethora of metabolic effects and might be released from several tissues involved in glucose homeostasis. They declared increased serum SFRP-4 levels several years before the clinical diagnosis of T2DM and proposed the possibility of using SFRP-4 as an early risk predictor indicating a therapeutic target for specific treatment of islet dysfunction. Hoffmann et al (23) showed that elevated SFRP-4 levels were associated with T2DM, metabolic syndrome, and severity of diabetes. The primary outcome was the composite of cardiovascular death and cardiovascular hospitalization within 48 months of follow-up. Comparison of event-free survival between SFRP-4 tertiles showed that SFRP-4 levels were not predictive for cardiovascular outcome in patients with stable CAD on treatment. Ji et al (24) found that plasma SFRP-4 levels were increased in CAD patients compared to non-CAD patients. Our results are similar; plasma SFRP-4 levels were positively correlated with BMI, fasting insulin levels and HOMA-IR values. CAD was an independent predictor of the increased plasma SFRP-4 levels. All results, including our results, suggest that SFRP-4 is a novel biomarker of CAD and might play a role in the development of CAD and DM due to the fact that SFRP-4 was up-regulated in patients with T2DM (15, 22-28).

GLP-1 has short half-lives, since they are rapidly degraded by DPP-4, a ubiquitous enzyme found in soluble form in plasma or as a membrane component of many cells (29), including endothelial cells (30). Elevated DPP-4 in patients with diabetes may justify, at least partially, the possibility that the status of incretin deficiency/resistance related to T2DM. DPP-4 inhibitors may potentially reduce cardiovascular (CV) risk. GLP-1, DPP-4 acts on other substrates, many of which are associated with cardiac protection in experimental models. Inhibition of DPP-4 may also lead to elevations in several substrates with potentially favorable effects on vascular function and anti-coagulation $(31,32)$. In our previous study (15), we have shown for the first time that diabetic patients with microvascular complications have higher DPP-4 activity and GLP- $1_{\text {total }}$ levels than diabetic patients without such complications. In the present study, the DPP-4 activity in CAD and CAD+DM groups is lower than in controls. GLP- $1_{\text {total }}$ levels in the control group is significantly higher than in $\mathrm{DM}, \mathrm{CAD}$ and CAD+DM groups. There was also a significant difference in GLP- $1_{\text {total }}$ between $\mathrm{CAD}+\mathrm{DM}$ and $\mathrm{DM}$ groups. A significantly weak positive correlation was found between DPP-4 and GLP- $1_{\text {total }}$ GLP- $1_{\text {total }}$ levels were negatively correlated with GLP- $1_{\text {active }}$ levels. DPP-4 activity in patients with T2DM showed conflicting results such as reduced $(33,34)$ or increased activity $(15,35-38)$. However, these disparate results may have occurred due to the use of drugs such as metformin and glitazones, which are both able to promote a decrease in DPP-4 activity $(31,39)$. Thus, the question whether increased or decreased DPP-4 and GLP-1 levels have beneficial or adverse pleiotropic effects on the CV system remains inconclusive. Different treatments may improve the pleiotropic effects of GLP-1 and DPP-4 on the CV system in patients with CAD+DM.

The power point of our study is that we evaluated the association between the concentrations of serum multiple biomarkers and CIMT and investigated whether these parameters have atherosclerotic effects in T2DM individuals. However, our study has some limitations. Firstly, our sample size is relatively small. Secondly, the dietary habits, physical activity and exercise levels of the subjects were not documented. Thirdly, we did not investigate cardiovascular comorbidities and drugs that could have affected our results. Due to the cross-sectional design of our study, we cannot make any suggestions about the association between the laboratory and clinical parameters of the subjects.

\section{Conclusion}

Patients with T2DM are at increased risk of cardiovascular disease. In addition to hyperglycemia which contributes to increased CV risk, patients with T2DM often have other conditions contributing to the development of cardiovascular complications such as hypertension and dyslipidemia (32). DPP-4 and SFRP-4 levels may be predictive markers for atherosclerosis in diabetes. They correlate well with HOMA-IR particularly in diabetes. CIMT has the potential to be a clinically useful predictor of vascular risk in diabetic patients with CAD. Large cohorts and at-risk populations are needed to confirm the predictive value of these findings.

\section{Reference}

1. Aronson D, Edelman ER. Coronary artery disease and diabetes mellitus. Cardiol Clin 2014; 32: 439-455.

2. Clodi M, Säly C, Hoppichler F, Resl M, Steinwender C, Eber B. Diabetes mellitus, coronary artery disease and heart disease. Wien Klin Wschr 2016; 128 Suppl 2: S212-215.

3. Li Q, Yang Z, Lu B, Wen J, Ye Z, Chen L, He M, Tao X, Zhang W, Huang Y, Zhang Z, Qu S, Hu R. Serum uric acid level and its association with metabolic syndrome and carotid atherosclerosis in patients with type 2 diabetes. Cardiovasc Diabetol 2011; 10: 72.

4. Matsagoura M, Andreadis E, Diamantopoulos EJ, Vassilopoulos C, Tentolouris N, Katsilambros N. Carotid intima-media thickness in patients with type 2 diabetes: the significance of microalbuminuria and different risk factors for atherosclerosis. Diabetes Care 2003; 26: 2966.

5. Cheng LJ, Xu ZR, Zhang Q, Wang ZD, Wu FW, Yang WX. Effects of comprehensive intensive therapies on the change of intima-media thickness of carotid arteries in type 2 diabetic patients: A report of 4-year follow-up with a literature review. Diab Vasc Dis Res 2016; 13: 31-40.

6. Zhang XX, Pan YH, Huang YM, Zhao HL. Neuroendocrine hormone amylin in diabetes. World J Diabetes 2016; 7: 189-197.

7. Bukhari SA, Shamshari WA, Ur-Rahman M, Zia-Ul-Haq M, Jaafar HZ. Computer aided screening of secreted frizzled-related protein 4 (SFRP4): a potential control for diabetes mellitus. Molecules 2014; 19: 10129-10136. 
8. Deacon CF, Ahren B, Holst JJ. Inhibitors of dipeptidyl peptidase IV: a novel approach for the prevention and treatment of Type 2 diabetes? Expert Opin Investig Drugs 2004; 13: 1091-1102.

9. Ahren B, Schmitz O. GLP-1 receptor agonists and DPP-4 inhibitors in the treatment of type 2 diabetes. Horm Metab Res 2004; 36: 867-886.

10. Ryskjaer J, Deacon CF, Carr RD, Krarup T, Madsbad S, Holst J, Vilsbøll T. Plasma dipeptidyl peptidase-IV activity in patients with type-2 diabetes mellitus correlates positively with HbAlc levels, but is not acutely affected by food intake. Eur J Endocrinol 2006; 155: 485-493.

11. Mackness B, Hunt R, Durrington PN, Mackness MI. Increased immunolocalization of paraoxonase, clusterin, and apolipoprotein A-I in the human artery wall with the progression of atherosclerosis. Arterioscler Thromb Vasc Biol 1997; 17: 1233-1238.

12. Ishikawa Y, Akasaka Y, Ishii T, Komiyama K, Masuda S, Asuwa N, Choi-Miura NH, Tomita M. Distribution and synthesis of apolipoprotein J in the atherosclerotic aorta. Arterioscler Thromb Vasc Biol 1998; 18: 665-672.

13. Daimon M, Oizumi T, Karasawa S, Kaino W, Takase K, Tada K, Jimbu Y, Wada K, Kameda W, Susa S, Muramatsu M, Kubota I, Kawata S, Kato T. Association of the clusterin gene polymorphisms with type 2 diabetes mellitus. Metabolism 2011; 60: 815-822.

14. American Diabetes Association. Diagnosis and classification of diabetes mellitus. Diabetes Care 2010; 33 (Supplement 1): S62-S69.

15. Senyigit A, Tabak O, Orhanoglu T, Karadag A, Ugurlu S, Uzun H, Konukoglu D. Glucagon-like peptide-1 levels and dipeptidyl peptidase-4 activity in type 2 diabetes. Clin Invest Med 2017; 40: E188-199.

16. Zheng X, Ren W, Zhang S, Liu J, Li S, Li J, Yang P, He J, Su S, Li P. Serum levels of proamylin and amylin in normal subjects and patients with impaired glucose regulation and type 2 diabetes mellitus. Acta Diabetol 2010; 47: 265-270.

17. Skovronsky DM, Lee VM-Y, Trojanowski JQ. Neurodegenerative diseases: new concepts of pathogenesis and theirtherapeutic implications. Annu Rev Pathol 2006; 1: 151-170.

18. Qiu WQ, Li H, Zhu H, Scott T, Mwamburi M, Rosenberg I, Rosenzweig J. Plasma Amylin and Cognition in Diabetes in the Absence and the Presence of Insulin Treatment. J Diabetes Metab 2014; 5(11). pii: 458.

19. Trougakos IP, Poulakou M, Stathatos M, Chalikia A, Melidonis A, Gonos ES. Serum levels of the senescence biomarker clusterin/apolipoprotein $\mathrm{J}$ increase significantly in diabetes type II and during development of coronary heart disease or at myocardial infarction. Exp Gerontol 2002; 37: $1175-1187$.

20. Cai R, Han J, Sun J, Huang R, Tian S, Shen Y, Dong X, Xia W, Wang S. Plasma Clusterin and the CLU Gene rs 11136000 Variant Are Associated with Mild Cognitive Impairment in Type 2 Diabetic Patients. Front Aging Neurosci 2016; 8: 179.

21. Seo JA, Kang MC, Ciaraldi TP, Kim SS, Park KS, Choe C, Hwang WM, Lim DM, Farr O, Mantzoros C, Henry RR, Kim YB. Circulating ApoJ is closely associated with insulin resistance in human subjects. Metabolism 2018; 78: 155-166.

22. Mahdi T, Hänzelmann S, Salehi A, Muhammed SJ, Reinbothe TM, Tang Y, Axelsson AS, Zhou Y, Jing X, Almgren P, Krus U, Taneera J, Blom AM, Lyssenko V, Esguerra JL, Hansson O, Eliasson L, Derry J, Zhang E, Wollheim CB, Groop L, Renström E, Rosengren AH. Secreted frizzled-related protein 4 reduces insulin secretion and is overexpressed in type 2 diabetes. Cell Metab 2012; 16: 625-633.

23. Hoffmann MM, Werner C, Böhm M, Laufs U, Winkler K. Association of secreted frizzled-related protein 4 (SFRP4) with type 2 diabetes in patients with stable coronary artery disease. Cardiovasc Diabetol 2014; 13: 155.
24. Ji Q, Zhang J, Du Y, Zhu E, Wang Z, Que B, Miao H, Shi S, Qin X, Zhao Y, Zhou Y, Huang F, Nie S. Human epicardial adipose tissue-derived and circulating secreted frizzled-related protein 4 (SFRP4) levels are increased in patients with coronary artery disease. Cardiovasc Diabetol 2017; 16: 133.

25. Liu F, Qu H, Li Y, Tang Q, Yang Z, Wang H, Deng H. Relationship between serum secreted frizzled-related protein 4 levels and the first-phase of glucose-stimulated insulin secretion in individuals with different glucose tolerance. Endocr J 2015; 62: 733-740.

26. Brix JM, Krzizek EC, Hoebaus C, Ludvik B, Schernthaner G, Schernthaner GH. Secreted frizzled-related protein 4 (SFRP4) is elevated in patients with diabetes mellitus. Horm Metab Res 2016; 48: 345-348.

27. Anand K, Vidyasagar S, Lasrado I, Pandey GK, Amutha A, Ranjani H, Mohan Anjana R, Mohan V, Gokulakrishnan K. Secreted frizzledrelated protein 4 (SFRP4): A novel biomarker of $\beta$-cell dysfunction and insulin resistance in individuals with prediabetes and type 2 diabetes. Diabetes Care 2016; 39: e147-148.

28. Bukhari SA, Shamshari WA, Ur-Rahman M, Zia-Ul-Haq M, Jaafar HZ. Computer aided screening of secreted frizzled-related protein 4 (SFRP4): a potential control for diabetes mellitus. Molecules 2014; 19: 10129-10136.

29. Holst JJ. On the physiology of GIP and GLP-1. Horm Metab Res 2004; 36: $747-754$.

30. Matheeussen V, Baerts L, De Meyer G, De Keulenaer G, Van der Veken P, Augustyns K, Dubois V, Scharpé S, De Meester I. Expression and spatial heterogeneity of dipeptidyl peptidases in endothelial cells of conduct vessels and capillaries. Biol Chem 2011; 392: 189-198.

31. Silva Júnior WS, Godoy-Matos AF, Kraemer-Aguiar LG. Dipeptidyl Peptidase 4: A new link between diabetes mellitus and atherosclerosis? Biomed Res Int 2015; 2015: 816164.

32. Koska J, Sands M, Burciu C, Reaven P. Cardiovascular effects of dipeptidyl peptidase-4 inhibitors in patients with type 2 diabetes. Diab Vasc Dis Res 2015; 12: 154-163.

33. Meneilly GS, Demuth HU, McIntosh CH, Pederson RA. Effect of ageing and diabetes on glucose-dependent insulinotropic polypeptide and dipeptidyl peptidase IV responses to oral glucose. Diabet Med 2000; 17: 346-350.

34. Korosi J, McIntosh CH, Pederson RA, Demuth HU, Habener JF, Gingerich R, Egan JM, Elahi D, Meneilly GS. Effect of aging and diabetes on the enteroinsular axis. J Gerontol A Biol Sci Med Sci 2001; 56: M575-579.

35. Ryskjaer J, Deacon CF, Carr RD, Krarup T, Madsbad S, Holst J, Vilsbøll T. Plasma dipeptidyl peptidase-IV activity in patients with type-2 diabetes mellitus correlates positively with HbAlc levels, but is not acutely affected by food intake. Eur J Endocrinol 2006; 155: 485-493.

36. Mannucci E, Pala L, Ciani S, Bardini G, Pezzatini A, Sposato I, Cremasco F, Ognibene A, Rotella CM. Hyperglycaemia increases dipeptidyl peptidase IV activity in diabetes mellitus. Diabetologia 2005; 48 : 1168-1172.

37. Vanderheyden M, Bartunek J, Goethals M, Verstreken S, Lambeir AM, De Meester I, Scharpé S. Dipeptidyl-peptidase IV and B-type natriuretic peptide. From bench to bedside. Clin Chem Lab Med 2009; 47: 248-252.

38. Lee SA, Kim YR, Yang EJ, Kwon EJ, Kim SH, Kang SH, Park DB, Oh BC, Kim J, Heo ST, Koh G, Lee DH. CD26/DPP4 levels in peripheral blood and T cells in patients with type 2 diabetes mellitus. J Clin Endocrinol Metab 2013; 98: 2553-2561.

39. Lenhard JM, Croom DK, Minnick DT. Reduced serum dipeptidyl peptidase-IV after metformin and pioglitazone treatments. Biochem Biophys Res Commun 2004; 324: 92-97.

Received November 9, 2018, Accepted January 23, 2019. 